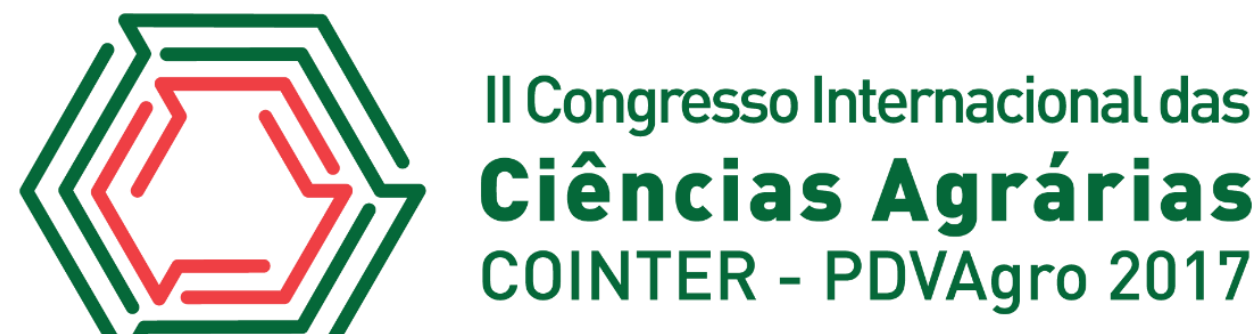

\section{AVALIAÇÃO DA ATIVIDADE FORMICIDA DO ÓLEO ESSENCIAL DE EUCALYPTUS $S P$. SOB DIFERENTES DOSAGENS}

\author{
Apresentação: Pôster \\ Jade Cristynne Franco Bezerra ${ }^{1}$; Ernandes Macedo da Cunha Neto²; Shirlene Cristina Brito \\ da Silva ${ }^{3}$; Marcos Samuel Matias Ribeiro ${ }^{4}$; Graziela Teixeira Oliveira ${ }^{5}$
}

\section{Introdução}

A utilização de produtos químicos de distintas classes toxicológicas é o método de controle mais usado contra pragas, entretanto, quando esse método é aplicado de forma continua e indiscriminada, causa severos problemas ambientais, dentre os quais se destaca o surgimento de patógenos resistentes e interrupção do controle biológico natural, favorecendo o surgimento de pragas secundárias (MENEZES, 2005; DINIZ et al., 2008). A utilização de extratos vegetais e/ou soluções naturais é uma nova forma de controle de pragas e tem se apresentado como uma pratica ecologicamente correta e viável (SZYMCZAK, et al., 2009).

$\mathrm{O}$ uso de plantas inseticidas tem uma vantagem especialmente para o pequeno produtor, pelo menor custo, facilidade de utilização, além disto, as plantas podem ser cultivadas na propriedade, facilitando sua utilização (MAZZONETTO \& VENDRAMIM, 2003).

Dentre as possíveis fontes vegetais, espécies de Eucalipto, gênero pertencentes à família Myrtaceae, têm sido bastante estudadas como fontes de óleos com bioatividade para serem utilizados como pesticidas naturais (BATISH et al., 2008).

A procura de novos produtos naturais com atividade inseticida é uma promissora abertura para as fitotoxinas e constituem uma alternativa ao desenvolvimento de bioinseticidas, diante disso, este estudo objetivou avaliar o possível efeito formicida do óleo essencial das folhas de Eucalyptus $s p$. sob diferentes dosagens visando à mitigação dos problemas ambientais gerados por agroquímicos.

\footnotetext{
${ }^{1}$ Discente de Engenharia Florestal, Universidade Federal Rural da Amazônia, jadefranco9@gmail.com

${ }^{2}$ Discente de Engenharia Florestal, Universidade Federal Rural da Amazônia, netomacedo9@gmail.com

${ }^{3}$ Graduada em Ciências biológicas, Universidade Federal Rural da Amazônia, shirlene.brito@ufra.edu.br

${ }^{4}$ Mestre em Ciências Climáticas, Universidade Federal Rural da Amazônia, marcos.matias@ufra.edu.br

${ }^{5}$ Mestre em Ciências da Saúde, Universidade Federal Rural da Amazônia, graziela.to@ hotmail.com
} 


\section{Fundamentação Teórica}

Algumas plantas não são cortadas pelas formigas e um dos fatores responsáveis por essa seleção é a presença de metabólitos secundários tóxicos para as formigas (HUBBELL et al., 1983). Baseados nessa informação, algumas pesquisas vêm sendo realizadas na tentativa de se isolar moléculas com atividades formicidas visando a um controle efetivo e redução do impacto ambiental (GODOY et al., 2002).

As formigas do gênero Atta, conhecidas popularmente como saúvas, possuem na parte superior do tórax de dois a três pares de espinhos e chegam a atingir $15 \mathrm{~mm}$ de comprimento (COSTA et al., 2008). Cortam totalmente limbos foliares e os transportam a seus ninhos para o cultivo de fungos simbiontes, dos quais se alimentam (GALLO et al., 2002). Em razão da existência de várias colônias em uma área, da grande quantidade de indivíduos por sauveiro, da sua voracidade e do difícil manejo, a saúva cabeça-de-vidro, Atta laevigata Smith (Hymenoptera: Formicidae), destaca-se como uma das principais espécies de formigas cortadeiras e como uma das principais espécies causadoras de danos econômicos nos sistemas agrícolas e florestais. Tornou-se a principal praga das florestas plantadas brasileiras, afetando a produção final e acarretando gastos intensos de controle (COSTA et al., 2008).

\section{Metodologia}

\section{Obtenção das plantas e preparo dos extratos}

O óleo essencial foi extraído no laboratório multidisciplinar quatro da Universidade federal Rural da Amazônia, campus Paragominas, pelo processo de arraste a vapor em um equipamento adaptado para esse fim (processo adaptado ao descrito por GUIMARÃES et al., 2000). As folhas para extração foram coletadas em um povoamento florestal de Eucalyptus sp. localizados no bairro Juparanã, no município de Paragominas-PA. As folhas coletadas foram submetidas à extração no mesmo dia, de modo que se utilizava sempre folhas frescas. No qual se realizou dez extrações contendo cento e dez gramas de folhas picadas para 2,5 litros de água destilada em cada extração.

\section{Coleta das formigas}

Foram coletadas 180 formigas nas dependências da Universidade federal Rural da Amazônia, campus Paragominas, por meio de armadilhas enterradas no chão. Posteriormente as formigas foram identificadas no laboratório de entomologia e submetidas ao ensaio experimental.

\section{Ensaio experimental}

O ensaio experimental (figura 1) consistiu na adaptação da metodologia de BRITO et al. 
(2006), no qual as formigas foram dispostas em seis potes de $250 \mathrm{ml}$ contendo diferentes dosagens de óleo essencial e água para volume final de $25 \mu$ embebido em papel filtro de tamanho $2 \times 2$ com auxilio do micropipetador (tabela 1), de modo que em cada pote foi colocado dez formigas da espécie Atta. Laevigata. Além disso, o ensaio foi realizado em triplicata para melhor obtenção dos resultados, de modo que para cada tratamento há um total de trinta indivíduos.

Tabela 1: Distribuição de dosagens de óleo essencial em $(\mu \mathrm{L})$ por pote. Fonte: própria

\begin{tabular}{lllllll}
\hline Pote & 1 & 2 & 3 & 4 & 5 & 6 \\
Dosagem & 0 & 5 & 10 & 15 & 20 & 25 \\
\hline
\end{tabular}

Figura 2: Ensaio experimental para avaliação do óleo essencial de Eucalyptus sp.. Fonte: própria

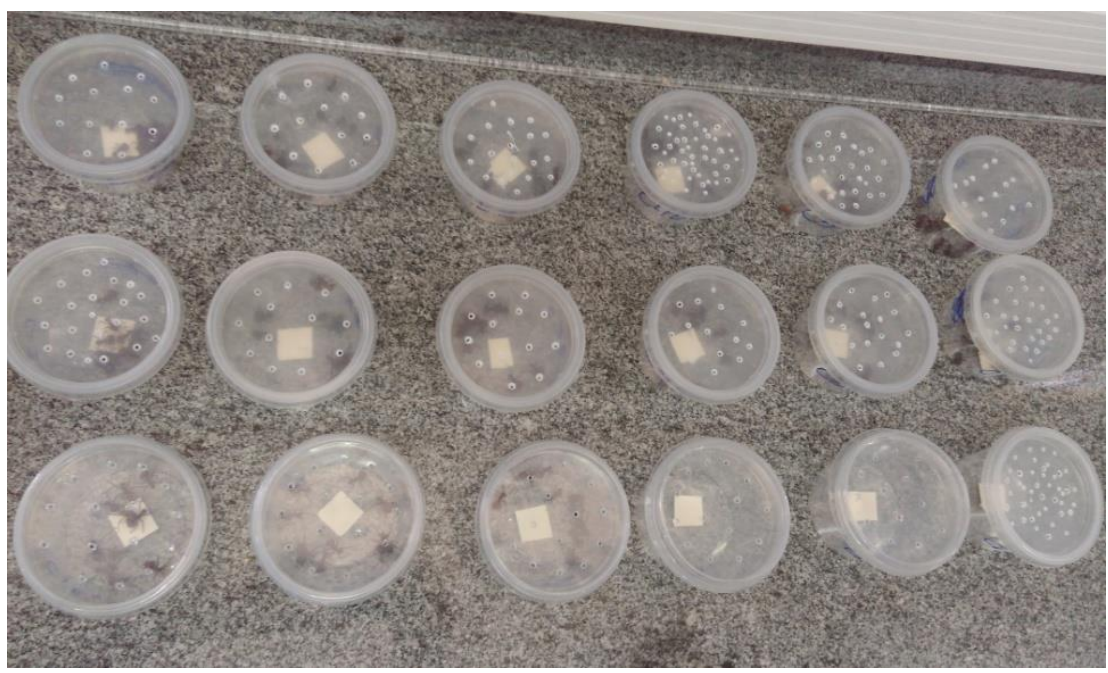

Os potes foram condicionados em temperatura de $20 \pm 2^{\circ} \mathrm{C}$. A avaliação consistiu em observar o número de indivíduos vivos e mortos, pela incapacidade de locomoção. Essa analise foi feita a cada 2 horas até 12 horas, depois, em intervalos de 6 horas, até 24 horas.

\section{Resultados e Discussões}

O rendimento do óleo essencial foi de $0,027 \mathrm{ml} . \mathrm{g}^{-1}$ da folha fresca de eucalipto, tendo obtido um total de $30 \mathrm{ml}$.

Através da analise visual dos potes, constatou que nos tratamentos que continham o óleo essencial, as formigas foram para as extremidades dos potes (figura $2 b$ ), de modo a se afastarem do papel filtro, entretanto, as formigas do tratamento controle (contendo apenas água) não demonstraram tal comportamento, pois muitas permaneciam sobre o papel filme (figura $2 a$ ). 
Figura 2: Reação dos indivíduos de A. Laevigata ao óleo essencial de Eucalyptus sp.. Fonte: própria

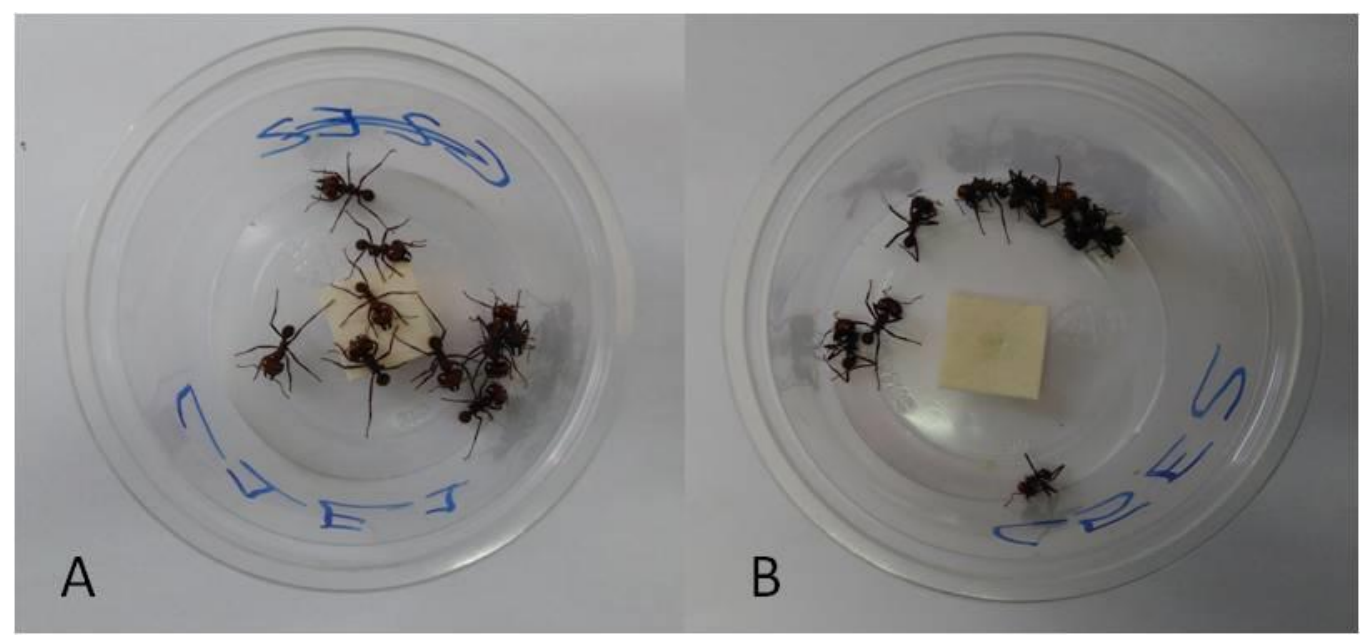

A tabela 2 apresenta a o percentual da mortalidade dos indivíduos de A. Laevigata nos tempos analisados para as doses de $0,5,10,15,20$ e $25 \mu \mathrm{L}$ do óleo essencial de Eucalyptus sp. A dose de $5 \mu \mathrm{L}$ se mostra suficiente, uma vez que com 4 horas mata 100\% dos insetos. Entretanto, nos potes contendo o tratamento controle não houve a morte de nenhum individuo, permanecendo vivos e ativos até o final do experimento.

Tabela 2: Percentual de mortalidade dos indivíduos da espécie Atta Laevigata nos intervalos analisados. Fonte: própria

\begin{tabular}{lll}
\hline Dosagem $(\mu \mathrm{L})$ & Tempo $(\mathrm{h})$ & Mortalidade $(\%)$ \\
\hline 0 & 2 & $0 \%$ \\
5 & 2 & $37 \%$ \\
10 & 2 & $23 \%$ \\
15 & 2 & $20 \%$ \\
20 & 2 & $30 \%$ \\
25 & 2 & $43 \%$ \\
\hline 0 & 4 & $0 \%$ \\
5 & 4 & $100 \%$ \\
10 & 4 & $100 \%$ \\
15 & 4 & $100 \%$ \\
20 & 4 & $100 \%$ \\
25 & 4 & $100 \%$ \\
\hline
\end{tabular}

\section{Conclusões}

O óleo essencial de Eucalyptus sp. mostrou-se eficiente no controle da formiga A. Laevigata, de modo que essa substancia apresenta um potencial no uso alternativo aos defensivos químicos, contribuindo com a mitigação dos problemas ambientais gerados por esses agroquímicos. 


\section{Referências}

BATISH, D. R.; HARMINDER, P. S.; KOHLI, R. K.; KAUR, S. Eucalyptus essential oil as a natural pesticide. Forest Ecologyand Management, 256, p.2166-2174, 2008.

BRITO, J. P.; OLIVEIRA, J. E. M.; BORTOLI, S. A. Toxicidade de óleos essenciais de Eucalyptus spp. sobre Callosobruchus maculatus (Fabr., 1775) (Coleoptera: Bruchidae). Anais da Revista de Biologia e Ciências da Terra, Jaboticabal, v. 6, n. 1, p.96-103, jun. 2006.

COStA, E. C; AVILA, M., CANTARElli, E. B., MURARI, A. B., MANZONI, C. G., Entomologia Florestal. Rio Grande do Sul: Editora UFSM; 2008.

GUIMARÃES, P. I. C.; OLIVEIRA, R. E. C.; ABREU, R. G. Extraindo óleos essenciais de plantas. Química nova na escola. n.1, p.45-46. 2000.

DINIZ, S. P. S. S.; Bioatividade do óleo essencial de Menthaarvensis L. no controle de fungos fitopatógenos. Anais da Revista Brasileira de Plantas Medicinais, Botucatu, v.10, n.4, p.9-11, 2008.

GALLO, D.; NAKANO, O, SILVEIRA NETO, S., CARVALHO, R. P. L., BATISTA G. C, BERTI FILHO, E, et al. Entomologia Agrícola. São Paulo: Editora FEALQ; 2002.

GODOY, M.F.P.; SOUZA, R.C.; ZANCUL, M.S.; PAGNOCCA, F.C.; FERNANDES, J.B.; BUENO, O.C.; HEBLING, M.J.A.; BACCI JUNIOR, M.; SILVA, M.F.G. da; VIEIRA, P.C. Toxicidade de Pilocarpus grandiflorus para o fungo simbionte de Atta sexdens. Arq. Inst. Biol., São Paulo, v.69, supl., p.192-194, 2002.

HUBBELL, S. P.; WIEMER, D. F.; ADEJARE, A. An antifungal terpenoid defends a neotropical tree (Hymenaeae) against attack by fungus growing ants (Atta). Oecologia, Berlin, v.60, p.321-327, 1983.

MAZZONETTO, F.; VENDRAMIM, J. D. Efeito de pós de origem vegetal sobre Acanthoscelidesobtectus (Say) (Coleoptera: Bruchidae) em feijão armazenado. Neotropical Entomology, v.32, p.145-149, 2003.

MENEZES, E. L. A. Inseticidas botânicos: seus princípios ativos, modo de ação e uso agrícola. Seropédica: Embrapa Agrobiologia, 2005.

SZYMCZAK, L. S.; et. al.; Efeito de Inseticidas Orgânicos sobre o Pulgão Aphisgossypii (Hemiptera: Aphididae) na Cultura do Pepino (Cucumissativus) em Condições de Laboratório; Revista Brasileira De Agroecologia. v.4, n. 2. UNICENTRO, 2009. 